\title{
Sunlight exposure during leisure activities and risk of prostate cancer in Montréal, Canada, 2005-2009
}

\author{
Jennifer $\mathrm{Yu}^{1,2}$, Jérôme Lavoué ${ }^{\text {and Marie-Élise Parent }}{ }^{2^{*}}$
}

\begin{abstract}
Background: Prostate cancer (PCa) is the leading cause of cancer in men in many developed countries, but no modifiable risk factors have been identified. A handful of analytical studies have suggested a possible etiological role for sunlight exposure. We report here on the association between leisure-time sunlight exposure during adulthood and PCa risk in the context of a population-based case-control study.

Methods: In all, 1,904 PCa cases were ascertained across Montreal French hospitals between 2005 and 2009. Concurrently, 1,962 population controls, frequency matched to cases by age ( \pm 5 years), were selected from the electoral list for French-speakers in Greater Montreal. Interviews elicited the frequency of engagement in any leisure activity during adulthood. This was used to derive cumulative sunlight exposure indices: a cumulative number of leisure activities events entailing sunlight exposure and a cumulative duration of sunlight exposure during leisure activities. Unconditional logistic regression was conducted to yield odds ratios (OR) and 95\% confidence intervals (CI) for estimating the association between sunlight exposure indices and PCa risk, adjusting for age, ancestry, family history of PCa, PCa screening, education, solar protection, body mass index and physical activity.
\end{abstract}

Results: Compared with men in the upper quartile category for the number of sunlight exposure events, men never exposed during leisure time had an OR of 1.32 (95\% Cl: 0.82-2.14). ORs were 1.11, 0.91 and 1.00 for the first to the third quartiles of exposure, respectively. Similar results were observed for cumulative duration of exposure to sunlight, and by PCa aggressiveness.

Conclusion: These findings provide little evidence of an association between sunlight exposure during leisure-time and PCa risk. Men with no sunlight exposure appeared at somewhat higher risks but none of the estimates achieved statistical significance.

Keywords: Prostate cancer, Sunlight exposure, Leisure, Epidemiology

\section{Background}

Prostate cancer ( $\mathrm{PCa}$ ) is the leading cause of cancer among men in Canada [1], and in many other developed countries [2]. Despite extensive research, the only clearly established risk factors thus far are increasing age, being of African ancestry, and having a first-degree family history of $\mathrm{PCa}[2,3]$. However, none of these factors lend themselves to disease prevention. One striking observation comes from migrant studies, which suggest that

\footnotetext{
* Correspondence: marie-elise.parent@iaf.inrs.ca

${ }^{2}$ INRS-Institut Armand-Frappier, Université du Québec, Laval, Québec H7V 1B7, Canada

Full list of author information is available at the end of the article
}

emigrants tend to acquire the PCa risks of their host countries $[4,5]$. This argues for a role of environmental influences, one of which might be sunlight exposure. While the latter has been predominantly linked to an increased risk of skin cancer, a handful of studies have suggested a protective effect of sunlight exposure for other cancers, including breast cancer [6-8].

Epidemiological evidence for a role of sunlight exposure in PCa incidence remains sparse. The majority of previous studies were of ecological design [6,9-13]. All of these studies, except one [13], suggested a protective effect of sunlight exposure. However, results from the few analytical studies conducted to date, using different 
sunlight exposure assessment methods, are inconsistent, documenting an inverse association [14-17], no association [18], or a positive association between sunlight exposure and PCa risk $[19,20]$. Whether sunlight exposure is actually involved in PCa development remains to be clarified through analytical studies based on strong study designs.

In Quebec, leisure activities represent the main source of sunlight exposure. Less than $8 \%$ of workers were reportedly exposed to solar ultraviolet radiation in that province [21]. We present here findings on the association between sunlight exposure, as incurred during outdoor leisure activities across adulthood, and PCa risk, in the context of a population-based case-control study conducted in Montréal, Canada.

\section{Methods}

This analysis is part of PROtEuS (Prostate Cancer \& Environment Study), a large scale research project aimed at elucidating the possible role of environmental, occupational, lifestyle, and genetic factors in the development of PCa. This study has been described previously [22].

\section{Study population}

The study was set in Montreal, where over $86 \%$ of residents speak French [23]. Cases were actively ascertained through pathology departments in major French hospitals, representing over $80 \%$ of all PCa patients diagnosed in the Montreal metropolitan area. Eligible cases were men under 76 years of age, with a first diagnosis of primary prostate adenocarcinoma between September 2005 and December 2009. Concurrently, population controls were randomly selected from Quebec's permanent French electoral list and frequency matched to cases by age ( \pm 5 years). They had no history of PCa. To be eligible, both cases and controls had to be Canadian citizens registered on the provincial electoral list, and to be residents in the Montreal metropolitan area.

Response rates were $79 \%$ and 56\% among eligible cases and controls, respectively. Reasons for non-participation among cases and controls were refusal (93\% and $86 \%$, respectively), unable to trace $(2 \%$ and $11 \%$, respectively), death with no available proxy ( $2 \%$ and $1 \%$, respectively), language barrier ( $2 \%$ for both), and too sick with no available proxy ( $1 \%$ for controls only) and other $(0.1 \%$ for controls only). Proxy respondents provided information for $3 \%$ and $4 \%$ of cases and controls, respectively. The study was approved by the ethics committees of all collaborating institutions (see Additional file 1: Ethics statement), and subjects provided written informed consent.

\section{Data collection}

Face-to-face interviews elicited detailed information on a wide range of socio-demographic, lifestyle and environmental factors. The degree of $\mathrm{PCa}$ aggressiveness, as defined by the Gleason score [24], was extracted from pathology reports.

Of relevance to the current analysis, subjects were asked to provide details about prior engagement in any activity or hobby during their leisure time, over their entire adulthood. Specific questions first elicited whether subjects had participated regularly, for at least 6 month, in any of 16 common leisure activities including sports, hobbies and household activities, since they were 18 years of age. Additional questions probed for corresponding information about any other performed hobby or leisure activity not included in the pre-defined list. For each activity reported, subjects were asked when they started and stopped doing the activity, the number of months per year, the frequency per day, week or month. Interruptions and changes in frequency for each activity over the entire adulthood were recorded. The information was used to derive detailed cumulative indices of exposure to sunlight during leisure (see below).

In addition, subjects were asked to self-report their overall frequency of direct exposure to sunlight, separately for leisure time and work time (never, sometimes, and often). Further questions assessed whether subjects used solar protection, such as using sun cream, wearing long sleeves, seeking shelter, etc. when directly exposed to sunlight during leisure as well as at work (never, sometimes, often).

Semi-quantitative assessments of overall physical activity levels during adulthood were elicited from subjects for three types of circumstances, i.e., at home, during leisure-time, and at work (not very active, moderately active, very active). These were combined into a composite index of overall physical activity level for each subject (low, medium, high).

\section{Sunlight exposure assessment}

Sunlight exposure indices were derived from questionnaire information on leisure-time activities. Activities used to assign sunlight exposure were those considered to have been performed outdoors most of the time. The most frequent included sports (walking for exercise, jogging, golf, racket sports, swimming, skiing/skating, cycling, etc.), and gardening and domestic chores (lawn mowing, snow removal, etc.); 108 other types of activities were reported as well (See Additional file 2: Table S1). Some activities, including swimming, could be performed indoor and/or outdoor. Judgment was applied to categorize them as entailing sunlight exposure or not based on the reported frequency and typical circumstances in the Montreal population.

Each leisure-time activity entailing exposure to sunlight is referred to hereafter as an "event". We calculated, for each subject, two indices of cumulative exposure to 
sunlight during adulthood. The first index was based on the cumulative number of events (CEvents), as follows:

$$
\begin{aligned}
\text { CEvents }= & \sum_{i=1}^{m}\left(\text { Frequency of event }_{i} \times\right. \text { Number of } \\
& \text { months } \left._{i} / 12 \times \text { Duration in years }{ }_{i}\right)
\end{aligned}
$$

where $i$ is an individual event, $m$ is the total number of different types of events, Frequency of event is the number of events per year, Number of months is the number of months per year the event occurred, and Duration in years is the total number of years of engagement in the event.

The amount of time subjects spent during each leisure activity event could vary both between and within activities, thereby influencing exposure duration per event. To better reflect important differences in duration per event, and to estimate the cumulative number of hours of engagement in activities, we assigned a typical duration to each type of activity based on expected average practices in the study population. For instance, 1 hour was assigned to walking, jogging, swimming and domestic chores requiring physical effort, 2 hours to racket sports, cycling and gardening, 3 hours to skiing or skating and 4 hours to golf. This enabled us to derive a second index based on the cumulative duration of exposure (CDuration):

$$
\begin{aligned}
\text { CDuration }= & \sum_{i=1}^{m} \text { (Frequency of event } t_{i} \times \text { Duration } \\
& \text { of event in hours } \text { i }_{i} \times \text { Number of months }_{i} / \\
& \left.12 \times \text { Duration in years } s_{i}\right)
\end{aligned}
$$

Where Duration of event in hours is the typical number of hours of engagement attributed to each event.

Some activities were carried out on a seasonal basis. However, information on this was only introduced in the questionnaire one year into the study, by requesting the number of months of participation in each activity over the year. Imputations were thus applied for number of months for the 304 cases and 196 controls with a missing value, reflecting usual patterns from the study base: 12 months per year for walking and domestic chores demanding physical efforts, 6 months per year for jogging, golf, biking and gardening, and 4 months per year for swimming, skiing and skating.

\section{Statistical analysis}

PROtEuS called upon the participation of 1,937 cases and 1,995 controls; subjects with missing information on recreational activities ( 1 case, 1 control), or on one or several covariates (32 cases, 32 controls) were excluded, leaving 1,904 cases and 1,962 controls for analyses. P-values of respective $\mathrm{T}$ tests and Chi-square tests were used to describe the distribution of cases and controls for different variables. A p-value of less than 0.05 designated statistical significance.

Unconditional logistic regression was used to estimate odds ratios (OR) and corresponding 95\% confidence intervals (CI) for the association between the two sunlight exposure indices and PCa risk. Subjects were categorized into five sunlight exposure groups, i.e., unexposed subjects, and exposed subjects distributed into quartiles according to the distribution among exposed controls. The upper quartile of exposure was chosen as the reference category because of the small number of unexposed subjects.

Models were adjusted on a set of a priori variables, i.e., age (continuous), first-degree family history of $\mathrm{PCa}$ (no, yes, don't know), ancestry (European, African, Asian, Other), and timing of the last $\mathrm{PCa}$ screening (2 years earlier, > 2 years earlier, not screened, don't know). A step-wise forward approach and the Akaike Information Criterion (AIC) [25] were used to identify other covariates to be included in the final models. Variables tested included educational level (elementary, high school, college, university), body mass index (BMI) 2 years before the index date (continuous), solar protection during leisure (never, sometimes, often) and at work (never, sometimes, often), self-reported occupational sunlight exposure (never, sometimes, often) and overall physical activity level (low, medium, high). Solar protection at work and selfreported occupational sunlight exposure were not retained since they did not appreciably improve the fit of the model.

Stratified analyses according to Gleason scores were conducted to evaluate the association between sunlight exposure and $\mathrm{PCa}$ according to disease aggressiveness. Non-aggressive PCa was defined by a Gleason score of 6 or lower, or a score of 7 with a primary score of 3, whereas aggressive PCa was defined by a Gleason score of 7 with a primary score of 4 , or a score of 8 or higher [26].

Sensitivity analyses were performed by excluding 1) proxy respondents, 2) controls who had not been screened for $\mathrm{PCa}$ in the two years before interview, and 3) subjects who were not asked about the number of months per year for each leisure activity. Other analyses evaluated the impact of considering participation to winter leisure activities as nonexposed to the sun, and using the self-reported sunlight exposure during leisure instead of the main exposure indices (CEvents and CDuration).

Statistical analyses were carried out using the R 2.15.1 statistical software $[27,28]$. 


\section{Results}

Selected characteristics of cases and controls are presented in Table 1. There were slight differences between cases and controls in terms of age, ancestry, BMI, family history of $\mathrm{PCa}$ and timing of last PCa screening, while other factors such as education, family income, smoking, alcohol consumption patterns and prevalence of skin cancer (melanoma and non-melanoma skin cancers) did not differ. While the study population was primarily of European ancestry, cases were more often of European or African ancestries, and less often of Asian ancestry, than controls. Cases were twice as likely as controls to have a first-degree family relative with PCa. PCa screening was common in this study population, with nearly all cases and over $76 \%$ of controls having been screened in the two years preceding diagnosis or interview. Selfreported overall physical activity levels during adulthood were similar amongst cases and controls.

Table 2 presents sunlight exposure patterns of study subjects. The proportions of cases and controls reporting to have never engaged in any leisure-time activities entailing sunlight exposure during adulthood were $2.9 \%$ and $2.7 \%$, respectively. Over half of study subjects reported having engaged in more than three different types of outdoor activities, while the remaining reported between 1 and 3 different types of activities, with similar distributions between cases and controls.

The median cumulative number of sunlight exposure events, as derived from CEvents, was 6,432 events (range $=24$ to 94,890 ) for exposed cases and 6,643 events (range $=24$ to 79,190 ) for exposed controls. The median cumulative duration of leisure-time exposure to sunlight, as derived from CDuration was 9,490 hours (range $=24$ to 103,500) among exposed cases and 9,712 hours (range $=$ 36 to 86,400) among exposed controls. CEvents and CDuration were highly correlated with one another (Spearman's $\rho=0.97$ ).

When subjects were asked to rate their typical frequency of exposure to sunlight, six percent of the cases and controls reported never having been exposed to sunlight during leisure, while about half of the subjects reported to having been often exposed. Almost two-thirds of cases and controls reported having never been exposed to sunlight at work; about $17 \%$ of subjects reported having often had sunlight workplace exposure.

About half of sunlight-exposed subjects reported never having used any protection during leisure time; $86 \%$ of men indicated having never used protection when exposed at work.

\section{Association between leisure-time sunlight exposure and PCa risk}

Table 3 presents associations between the two indices of sunlight exposure during leisure time and $\mathrm{PCa}$ for the whole sample, and by disease aggressiveness. Compared to men who had ever been exposed to sunlight during leisure time activities during adulthood, those who had never been exposed had an OR for PCa of 1.30 (95\% $\mathrm{CI}=0.83-2.06)$. In analyses considering quartiles of sunlight exposure, and using the upper quartile as the referent category, there were no statistically significant associations for any of the exposure categories, and PCa. Nor was there evidence of a dose-response pattern. This held true for both cumulative indices, CEvents and CDuration.

Similar results were obtained upon stratifying by PCa aggressiveness (Table 3). In addition, all five sensitivity analyses (Table 4) showed results comparable with those from the main analyses.

\section{Discussion}

There was little evidence of an association between sunlight exposure during leisure-time and $\mathrm{PCa}$ risk in our data. Men never exposed to sunlight during leisure-time appeared to be at slightly higher risk of PCa than those who had been exposed at some point during adulthood, but none of the estimates achieved statistical significance.

The epidemiological evidence available to date on the association between sunlight exposure and PCa risk remains contentious. Some previous studies have looked at this association in terms of PCa mortality [29-34]. Since the latter can reflect both survival and etiology, findings from these are not expected to necessarily align with our own, which focuses on PCa incidence.

Of studies assessing the risk of incident PCa [6,9-20,35], many were in line with a protective effect of sunlight. However, the majority used an ecological approach, with confounding remaining of major concern [36], especially when studying sunlight exposure and cancer risk [13].

To our knowledge, only eight analytical studies of incident PCa have been conducted to date on this issue [14-20,35]. Study design, size and sunlight assessment protocols have varied widely. Five of these support a protective effect of sunlight. Two were case-control studies, one [14] assessing exposure to sunlight residential, work and recreational settings as part of interviews (450 cases, 455 controls), the other [35] assessing cumulative sunlight exposure per year and sunbathing frequency (453 cases, 312 controls). Three cohort studies also reported a protective effect of sunlight. The first was based on 153 PCa cases, and estimated residential sunlight ambient levels [15]. The second, including 161 PCa cases, assessed solar radiation levels at birth address and reports of sunlight exposure during leisure and at work [16]. More recently, a third and much larger cohort study accrued over 21,000 incident PCa cases during the period of follow-up [17]. This investigation assessed ambient ultraviolet radiation levels at the residence of subjects 
Table 1 Selected characteristics of 1,904 cases and 1,962 controls, PROtEuS, Montreal, Canada

\begin{tabular}{llllll}
\hline Characteristics & \multicolumn{3}{l}{ Cases } & \multicolumn{3}{l}{ Controls } & p-values \\
\hline $\begin{array}{l}\text { Age in years, mean (SD) } \\
\text { Ancestry, } n(\%)\end{array}$ & 63.5 & $(6.8)$ & 64.8 & $(6.9)$ & $<0.01^{\mathrm{d} *}$ \\
$\quad$ & & & & & $<0.01^{\mathrm{e}^{*}}$ \\
$\quad$ African & 125 & $(6.6)$ & 86 & $(4.4)$ & \\
$\quad$ Asian & 24 & $(1.3)$ & 71 & $(3.6)$ & \\
$\quad$ European & 1681 & $(88.3)$ & 1674 & $(85.3)$ \\
Other & 74 & $(3.9)$ & 131 & $(6.7)$
\end{tabular}

Family income in \$CAD, $n(\%)$

$<10,000$

$10,000-19,999$

20,000-29,999

$30,000-49,999$

$50,000-79,999$

$80,000-100,000$

$>100,000$

Unknown

Education, $\mathrm{n}(\%)$

Primary school or less

High school

College

University

$\mathrm{BMI}$ in $\mathbf{k g} / \mathbf{m}^{2}$, mean (SD)

Ever smoker ${ }^{\mathrm{a}}, \mathrm{n}(\%)$

No

Yes

Unknown

Ever drinker ${ }^{\mathbf{b}}, \mathrm{n}(\%)$

Reported overall physical activity level at work $n(\%)$

Not very active
Moderately active
Very active

Reported overall physical activity level during leisure time, $\mathrm{n}(\%)$

Not very active
Moderately active

Very active

Unknown

Reported overall physical activity level at home, $n(\%)$

Not very active

Moderately active

Very active

Unknown $\begin{array}{llll}74 & \text { (3.9) } & 131 & (6.7)\end{array}$

$\begin{array}{llll}55 & (2.9) \quad 59 & (3.0)\end{array}$

$\begin{array}{llll}162 & (8.5) \quad 176 & (9.0)\end{array}$

$259 \quad$ (13.6) $245 \quad(12.5)$

$442 \quad$ (23.2) $461 \quad$ (23.5)

$422 \quad(22.2) \quad 406 \quad(20.7)$

$\begin{array}{llll}172 & (9.0) & 165 & (8.4)\end{array}$

$252 \quad$ (13.2) $258 \quad$ (13.1)

$\begin{array}{llll}140 & (7.4) \quad 192 & (9.8)\end{array}$

$432 \quad(22.7) \quad 418 \quad(21.3)$

$\begin{array}{llll}575 & \text { (30.2) } & 570 & (29.1)\end{array}$

$310 \quad(16.3) \quad 370 \quad(18.9)$

$587 \quad(30.8) \quad 604 \quad(30.8)$

$26.8 \quad(4.0) \quad 27.2 \quad(4.4) \quad<0.01^{d *}$

$505 \quad$ (26.5) $501 \quad$ (25.5)

$1398 \quad(73.4) \quad 1461 \quad(74.5)$

$\begin{array}{llll}1 & (0.1) & 0 & (0.0)\end{array}$

$1697 \quad(89.1) \quad 1738 \quad(88.6) \quad 0.59^{e}$

$0.10^{\mathrm{e}}$

$\begin{array}{llll}407 \quad(21.4) & 424 & (21.6)\end{array}$

$\begin{array}{llll}565 & \text { (29.7) } & 639 & \text { (32.6) }\end{array}$

$\begin{array}{llll}932 & (48.9) & 899 & (45.8)\end{array}$

\section{$0.08^{\mathrm{e}}$}

$556 \quad(29.2) \quad 634 \quad(32.3)$

$908 \quad(47.7) 931 \quad(47.5)$

$439 \quad(23.1) \quad 396 \quad(20.2)$

$1 \quad(0.1) \quad 1 \quad(0.1)$ $0.01^{\mathrm{e} *}$

$520 \quad(27.3) \quad 592 \quad(30.2)$

$945 \quad(49.6) \quad 1001 \quad(51.0)$

$438 \quad(23.0) \quad 369 \quad(18.8)$

$1 \quad(0.1) \quad 0 \quad(0.0)$
Table 1 Selected characteristics of 1,904 cases and 1,962 controls, PROtEuS, Montreal, Canada (Continued)

\begin{tabular}{|c|c|c|c|c|c|}
\hline Had/have skin cancer', n (\%) & 62 & (3.3) & 56 & $(2.9)$ & $0.47^{e}$ \\
\hline $\begin{array}{l}\text { First-degree relative with } \\
\text { prostate cancer, } \mathrm{n}(\%)\end{array}$ & & & & & $<0.01^{\mathrm{e} *}$ \\
\hline No & 1409 & $(74.0)$ & 1723 & $(87.8)$ & \\
\hline Yes & 445 & (23.4) & 198 & $(10.1)$ & \\
\hline Unknown & 50 & (2.6) & 41 & $(2.1)$ & \\
\hline $\begin{array}{l}\text { Timing of last prostate cancer } \\
\text { screening, } n(\%)\end{array}$ & & & & & $<0.01^{\mathrm{e}_{*}}$ \\
\hline Not screened & 2 & $(0.1)$ & 184 & $(9.4)$ & \\
\hline Screened within the last 2 years & 1886 & $(99.1)$ & 1491 & $(76.0)$ & \\
\hline Screened more than 2 years ago & 1 & $(0.1)$ & 234 & $(11.9)$ & \\
\hline $\begin{array}{l}\text { Not sure if screened within the } \\
\text { last } 2 \text { years }\end{array}$ & 15 & $(0.8)$ & 53 & $(2.7)$ & \\
\hline \multicolumn{6}{|l|}{ Gleason score, n (\%) } \\
\hline$<6 / 10$ & 15 & $(0.8)$ & & & \\
\hline $6 / 10$ & 801 & $(42.1)$ & & & \\
\hline $7 / 10$ with primary score of 3 & 568 & (29.8) & & & \\
\hline $7 / 10$ with primary score of 4 & 269 & $(14.1)$ & & & \\
\hline $\begin{array}{l}\text { 7/10 with unknown primary } \\
\text { score }\end{array}$ & 8 & $(0.4)$ & & & \\
\hline $8 / 10-10 / 10$ & 243 & $(12.8)$ & & & \\
\hline
\end{tabular}

${ }^{\mathrm{a}}$ Smoked at least 100 cigarettes in lifetime. ${ }^{\mathrm{b}}$ Consumed at least one alcohol beverage per month for at least one year. Includes melanoma and non-melanoma skin cancers. ${ }^{\mathrm{d}} \mathrm{T}$ test. ${ }^{\mathrm{e}} \mathrm{Chi}$-square test. ${ }^{*} \mathrm{p}$-value lower than 0.05

at baseline. However, individual information on time spent outdoors, which can vary greatly between individuals and over time, was not available.

Another large investigation, a nested case-control study of 1,020 cases and 5,044 controls conducted in the UK, observed no association overall between reported time spent outside during childhood and adulthood, and PCa risk [18]. An inverse relationship was observed between $\mathrm{PCa}$ and intense sun exposure 2 years prior to the index date (all cancers), while time spent outside was associated with higher risks of advanced PCa.

Finally, two case-control studies documented an excess risk of $\mathrm{PCa}$ among individuals who had spent the greatest number of hours outdoor either recently [19], or at the ages of 30 and 50 years [20]. One [19] was conducted in Singapore (240 cases, 268 controls) while the other [20], in New South Wales, Australia (1084 cases and 234 controls). In both studies, positive associations were apparent for all cancers, as well as for aggressive ones [19]. It has been brought forward that a U-shaped relationship might reconcile apparent contradictions across studies, i.e., inverse or positive associations between sunlight exposure and $\mathrm{PCa}$ observed in low or high solar UV environments, respectively [20]. In our study, none of the sunlight exposure levels showed statistically significant associations with $\mathrm{PCa}$ and confidence 
Table 2 Sunlight exposure patterns of 1,904 cases and 1,962 controls, PROtEuS, Montreal, Canada

\begin{tabular}{|c|c|c|c|c|c|}
\hline \multirow{2}{*}{$\begin{array}{l}\text { Exposure } \\
\text { Individual types of outdoor leisure activities }{ }^{\mathrm{a}}\end{array}$} & \multicolumn{2}{|c|}{ Cases n (\%) } & \multicolumn{2}{|c|}{ Controls n (\%) } & \multirow[t]{2}{*}{ p-values } \\
\hline & & & & & \\
\hline Walking & 1206 & $(75.2)$ & 1246 & (63.5) & $0.91^{b}$ \\
\hline Jogging & 427 & (26.6) & 467 & (23.8) & $0.31^{b}$ \\
\hline Golf & 427 & $(26.6)$ & 449 & (22.9) & $0.73^{b}$ \\
\hline Racket sports & 538 & (33.5) & 527 & (26.9) & $0.33^{b}$ \\
\hline Swimming & 474 & $(29.6)$ & 450 & (22.9) & $0.15^{\mathrm{b}}$ \\
\hline Skiing/skating & 893 & $(55.7)$ & 842 & $(42.9)$ & $0.01^{\mathrm{b} *}$ \\
\hline Cycling & 1108 & $(69.1)$ & 1037 & (52.9) & $<0.01^{b *}$ \\
\hline Gardening & 765 & $(47.7)$ & 799 & $(40.7)$ & $0.73^{b}$ \\
\hline Domestic chores demanding physical effort & 1562 & $(97.4)$ & 1605 & $(81.8)$ & $0.85^{\mathrm{b}}$ \\
\hline Other & 367 & $(19.3)$ & 420 & $(21.4)$ & $0.10^{\mathrm{b}}$ \\
\hline Number of different types of outdoor leisure activities ${ }^{a}$ & & & & & $0.29^{c}$ \\
\hline 0 & 55 & $(2.9)$ & 52 & $(2.7)$ & \\
\hline $1-3$ & 678 & $(35.6)$ & 751 & $(38.3)$ & \\
\hline $4-11$ & 1171 & $(61.5)$ & 1159 & $(59.1)$ & \\
\hline Cumulative number of sunlight exposure events (CEvents) ${ }^{a}$ & & & & & $0.30^{c}$ \\
\hline None: 0 & 55 & $(2.9)$ & 52 & $(2.7)$ & \\
\hline Q1: 1-3,210 & 506 & $(26.6)$ & 478 & $(24.4)$ & \\
\hline Q2: 3,211-6,642 & 438 & $(23.0)$ & 477 & $(24.3)$ & \\
\hline Q3: 6,643-13,679 & 474 & $(24.9)$ & 477 & $(24.3)$ & \\
\hline Q4: $13,680-94,886.67$ & 431 & $(22.6)$ & 478 & $(24.4)$ & \\
\hline Cumulative number of hours exposed to sunlight (CDuration) ${ }^{\mathrm{a}}$ & & & & & $0.30^{c}$ \\
\hline None: 0 & 55 & $(2.9)$ & 52 & $(2.7)$ & \\
\hline Q1: 1-4,497 & 483 & $(25.4)$ & 478 & $(24.4)$ & \\
\hline Q2: 4,498-9,711 & 467 & $(24.5)$ & 477 & $(24.3)$ & \\
\hline Q3: 9,712-18,459 & 489 & $(25.7)$ & 476 & $(24.3)$ & \\
\hline Q4: $18,460-103,484$ & 410 & $(21.5)$ & 479 & $(24.4)$ & \\
\hline Self-reported sunlight exposure during leisure & & & & & $0.03^{\mathrm{b} *}$ \\
\hline Never & 105 & $(5.5)$ & 117 & $(6.0)$ & \\
\hline Sometimes & 708 & $(37.2)$ & 804 & $(41.0)$ & \\
\hline Often & 1091 & $(57.3)$ & 1041 & $(53.1)$ & \\
\hline Self-reported sunlight exposure at work & & & & & $0.12^{\mathrm{b}}$ \\
\hline Never & 1238 & $(65.0)$ & 1318 & $(67.2)$ & \\
\hline Sometimes & 345 & $(18.1)$ & 307 & $(15.6)$ & \\
\hline Often & 321 & $(16.9)$ & 337 & $(17.2)$ & \\
\hline Use of solar protection during leisure & & & & & $0.05^{\mathrm{b}}$ \\
\hline Never & 1009 & $(53.0)$ & 977 & $(49.8)$ & \\
\hline Sometimes & 485 & $(25.5)$ & 502 & (25.6) & \\
\hline Often & 410 & $(21.5)$ & 483 & (24.6) & \\
\hline Use of solar protection at work & & & & & $0.15^{\mathrm{b}}$ \\
\hline Never & 1643 & $(86.3)$ & 1684 & $(85.8)$ & \\
\hline Sometimes & 116 & $(6.1)$ & 101 & $(5.1)$ & \\
\hline Often & 145 & $(7.6)$ & 177 & $(9.0)$ & \\
\hline
\end{tabular}


Table 3 ORs $(95 \% \mathrm{Cl})^{\dagger}$ for the association between leisure-time sunlight exposure prostate cancer, PROtEuS, Montreal, Canada

\begin{tabular}{|c|c|c|c|c|c|c|c|c|c|c|c|}
\hline \multirow[b]{3}{*}{ Sunlight exposure index } & \multirow{2}{*}{\multicolumn{2}{|c|}{$\begin{array}{l}1,904 \\
\text { controls }\end{array}$}} & \multirow{2}{*}{\multicolumn{3}{|c|}{$\begin{array}{l}\text { All prostate cancers } \\
1,904 \text { cases and } 1,962 \text { controls }\end{array}$}} & \multirow{2}{*}{\multicolumn{3}{|c|}{$\begin{array}{l}\text { Non-aggressive prostate cancers }{ }^{\mathrm{b}} \\
1,384 \text { cases and } 1,962 \text { controls }\end{array}$}} & \multirow{2}{*}{\multicolumn{3}{|c|}{$\begin{array}{l}\text { Aggressive prostate cancers }^{c} \\
512 \text { cases and } 1,962 \text { controls }\end{array}$}} \\
\hline & & & & & & & & & & & \\
\hline & $\bar{n}$ & (\%) & $\bar{n}$ & $(\%)$ & OR $(95 \% \mathrm{CI})^{\mathrm{a}}$ & $\bar{n}$ & $(\%)$ & OR $(95 \% \mathrm{CI})^{\mathrm{a}}$ & $\bar{n}$ & (\%) & OR $(95 \% \mathrm{Cl})^{\mathrm{a}}$ \\
\hline \multicolumn{12}{|l|}{ CEvents $^{\mathrm{d}}$} \\
\hline None & 52 & $(2.7)$ & 55 & $(2.9)$ & $1.32(0.82-2.14)$ & 35 & $(2.5)$ & $1.29(0.76-2.20)$ & 19 & (3.7) & $1.53(0.79-2.87)$ \\
\hline Q1 & 478 & (24.4) & 506 & $(26.6)$ & $1.11(0.90-1.37)$ & 377 & $(27.2)$ & $1.12(0.89-1.41)$ & 128 & (25.0) & $1.09(0.79-1.50)$ \\
\hline Q2 & 477 & (24.3) & 438 & $(23.0)$ & $0.91(0.74-1.11)$ & 332 & $(24.0)$ & $0.94(0.75-1.17)$ & 105 & $(20.5)$ & $0.84(0.61-1.14)$ \\
\hline Q3 & 477 & (24.3) & 474 & $(24.9)$ & $1.00(0.82-1.22)$ & 324 & $(23.4)$ & $0.92(0.73-1.15)$ & 146 & $(28.5)$ & $1.19(0.89-1.59)$ \\
\hline \multirow[t]{2}{*}{ Q4 } & 478 & $(24.4)$ & 431 & $(22.6)$ & 1.00 (reference) & 316 & $(22.8)$ & 1.00 (reference) & 114 & (22.3) & 1.00 (reference) \\
\hline & & & & & $p$-trend $=0.56$ & & & $p$-trend $=0.57$ & & & $p$-trend $=0.58$ \\
\hline \multicolumn{12}{|l|}{ CDuration $^{\mathrm{e}}$} \\
\hline None & 52 & $(2.7)$ & 55 & $(2.9)$ & $1.38(0.86-2.23)$ & 35 & $(2.5)$ & $1.41(0.83-2.41)$ & 19 & (3.7) & $1.41(0.73-2.65)$ \\
\hline Q1 & 478 & (24.4) & 483 & $(25.4)$ & $1.10(0.89-1.37)$ & 363 & $(26.2)$ & $1.18(0.93-1.49)$ & 118 & (23.0) & $0.92(0.67-1.26)$ \\
\hline Q2 & 477 & (24.3) & 467 & $(24.5)$ & $0.99(0.81-1.22)$ & 333 & $(24.1)$ & $1.00(0.79-1.25)$ & 134 & $(26.2)$ & $0.99(0.73-1.33)$ \\
\hline Q3 & 476 & (24.3) & 489 & $(25.7)$ & $1.13(0.92-1.39)$ & 366 & $(26.4)$ & $1.20(0.96-1.50)$ & 119 & $(23.2)$ & $0.95(0.70-1.28)$ \\
\hline \multirow[t]{2}{*}{ Q4 } & 479 & (24.4) & 410 & $(21.5)$ & 1.00 (reference) & 287 & $(20.7)$ & 1.00 (reference) & 122 & $(23.8)$ & 1.00 (reference) \\
\hline & & & & & $p$-trend $=0.38$ & & & $p$-trend $=0.30$ & & & $p$-trend $=0.66$ \\
\hline
\end{tabular}

${ }^{\dagger}$ Odds ratios and $95 \%$ confidence intervals. ${ }^{a}$ Adjusted for age, first-degree family history of prostate cancer, ancestry, timing of last prostate cancer screening, education, BMI, solar protection during leisure and overall physical activity level. ${ }^{b}$ Prostate cancer cases with a Gleason score of 6 or lower or of 7 with a primary score of 3. 'Prostate cancer cases with Gleason score of 7 with a primary score of 4 or 8 or higher. ${ }^{d}$ Cumulative number of events entailing sunlight exposure from age 18 years to age at diagnosis for cases or age at interview for controls (levels: none: 0 event, Q1: 1 to 3,210 events, Q2: 3,211 to 6,642 events, Q3: 6,643 to 13,679 events, Q4: 13,680 to $94,886.67$ events). ${ }^{\text {eC }}$ (umulative duration of leisure-time exposure to sunlight from age 18 years to age at diagnosis for cases or age at interview for controls (levels: none: 0 hour, Q1: 1 to 4,497 hours, Q2: 4,498 to 9,711 hours, Q3: 9,712 to 18,459 hours, Q4: 18,460 to 103,484 hours).

intervals overlapped between exposure categories. However, men in the middle category tended to be at lesser risk of PCa compared to those in other categories. Tests assessing the linearity of the exposure variables or the presence of a U-shape association were negative (data not shown).

Previous studies present methodological differences with our own. One salient difference across previous investigations relates to the sunlight exposure assessment methods applied. Geographical-based sunlight exposure indices were used in ecological studies [6,9-12] as well as in some analytical studies [14-17]. The downside of such approaches is that ambient solar levels are assumed to reflect individual exposures, which may result in important misclassification of exposure. Individual-based exposure assessment methods used in previous studies include a self-reported recreational sun exposure level [16], a sun exposure index based on skin pigmentation [14], lifetime or adulthood frequencies of outdoor leisure activities in hours per week [14,19] and a sum of hours of sunlight exposure during summer weekends at two age points [20]. Although our sunlight exposure assessment may not be as precise as that used in some of the aforementioned studies, it was based on detailed questionnaire data eliciting participation in outdoor leisure activities. Changes in engagement in the different activities over the years were factored in, so were variations across seasons for most study subjects. However, we did not collect information on acute sunlight exposures (e.g. sunbathing), on sunlight exposure while traveling to work or elsewhere, or on the specific number of hours involved in each outdoor activity. Nevertheless, when we applied typical leisure activity event durations to differentiate between typically shorter and longer exposure events it had little impact on risk estimates as compared to the cumulative number of events. We had information on the reported overall sunlight exposure during work-time. Albeit resulting in a crude exposure index, workplace exposure had relatively low prevalence in our population and did not influence the association between leisure-time exposure and PCa.

Our study was based on the population living in Montreal, Canada, at a latitude entailing low solar radiation intensity [37]. It may be that our findings are not readily comparable with those observed among subjects living in different latitudes. Another difference relates to the ancestries represented in the different study populations. Our study predominantly included subjects of European ancestry, whereas, for instance, the Singapore study focused on Asians, a population known to have lower risks of $\mathrm{PCa}$ [38].

As is the case for any study evaluating risks or benefits associated with sunlight, exposure misclassification likely occurred to some extent in our data. However, it is 
Table 4 Sensitivity analyses for the association between leisure-time sunlight exposure and prostate cancer, PROtEuS, Montreal, Canada

\begin{tabular}{|c|c|c|c|c|c|}
\hline \multirow[b]{2}{*}{ Sensitivity analysis } & \multicolumn{2}{|c|}{ Cases } & \multicolumn{2}{|c|}{ Controls } & \multirow[b]{2}{*}{ OR $(95 \% \mathrm{CI})^{\mathrm{a}}$} \\
\hline & $\bar{n}$ & (\%) & $\bar{n}$ & $(\%)$ & \\
\hline Excluding proxy respondents & 1854 & $(100)$ & 1889 & $(100)$ & \\
\hline \multicolumn{6}{|l|}{ CEvents $^{\mathrm{b}}$} \\
\hline None: 0 event & 55 & (3.0) & 46 & $(2.4)$ & $1.45(0.89-2.38)$ \\
\hline Q1: 1 to 3,210 events & 490 & (26.4) & 456 & $(24.1)$ & $1.13(0.91-1.40)$ \\
\hline Q2: 3,211 to 6,642 events & 431 & $(23.2)$ & 463 & $(24.5)$ & $0.94(0.76-1.16)$ \\
\hline Q3: 6,643 to 13,679 events & 464 & $(25.0)$ & 460 & $(24.4)$ & $1.01(0.82-1.24)$ \\
\hline \multirow[t]{2}{*}{ Q4: 13,680 to $94,886.67$ events } & 414 & (22.3) & 464 & $(24.6)$ & 1.00 (reference) \\
\hline & & & & & $p$-trend $=0.52$ \\
\hline \multicolumn{6}{|l|}{ CDuration $^{c}$} \\
\hline None: 0 hour & 55 & (3.0) & 46 & $(2.4)$ & $1.52(0.94-2.50)$ \\
\hline Q1: 1 to 4,497 hours & 466 & $(25.1)$ & 457 & $(24.2)$ & $1.14(0.91-1.42)$ \\
\hline Q2: 4,498 to 9,711 hours & 459 & $(24.8)$ & 465 & $(24.6)$ & $1.01(0.82-1.25)$ \\
\hline Q3: 9,712 to 18,459 hours & 480 & $(25.9)$ & 457 & $(24.2)$ & $1.18(0.96-1.46)$ \\
\hline \multirow[t]{2}{*}{ Q4: 18,460 to 103,484 hours } & 394 & $(21.3)$ & 464 & $(24.6)$ & 1.00 (reference) \\
\hline & & & & & p-trend $=0.35$ \\
\hline Excluding controls not screened for prostate cancer & 1904 & $(100)$ & 1491 & $(100)$ & \\
\hline \multicolumn{6}{|l|}{ CEvents $^{\mathrm{b}}$} \\
\hline None: 0 event & 55 & $(2.9)$ & 34 & $(2.3)$ & $1.39(0.86-2.27)$ \\
\hline Q1: 1 to 3,210 events & 506 & (26.6) & 336 & $(22.5)$ & $1.12(0.91-1.39)$ \\
\hline Q2: 3,211 to 6,642 events & 438 & $(23.0)$ & 373 & $(25.0)$ & $0.88(0.72-1.09)$ \\
\hline Q3: 6,643 to 13,679 events & 474 & (24.9) & 374 & $(25.1)$ & $1.03(0.84-1.26)$ \\
\hline \multirow[t]{2}{*}{ Q4: 13,680 to $94,886.67$ events } & 431 & $(22.6)$ & 374 & $(25.1)$ & 1.00 (reference) \\
\hline & & & & & $p$-trend $=0.56$ \\
\hline \multicolumn{6}{|l|}{ CDuration $^{c}$} \\
\hline None: 0 hour & 55 & $(2.9)$ & 34 & $(2.3)$ & $1.49(0.92-2.45)$ \\
\hline Q1: 1 to 4,497 hours & 483 & $(25.4)$ & 339 & $(22.7)$ & $1.18(0.95-1.46)$ \\
\hline Q2: 4,498 to 9,711 hours & 467 & $(24.5)$ & 370 & $(24.8)$ & $1.00(0.81-1.23)$ \\
\hline Q3: 9,712 to 18,459 hours & 489 & (25.7) & 365 & $(24.5)$ & $1.19(0.97-1.46)$ \\
\hline \multirow[t]{2}{*}{ Q4: 18,460 to 103,484 hours } & 410 & $(21.5)$ & 383 & $(25.7)$ & 1.00 (reference) \\
\hline & & & & & $p$-trend $=0.32$ \\
\hline $\begin{array}{l}\text { Excluding subjects without information for number of months } \\
\text { per year of leisure activities }\end{array}$ & 1611 & $(100)$ & 1766 & $(100)$ & \\
\hline \multicolumn{6}{|l|}{ CEvents $^{\mathrm{b}}$} \\
\hline None: 0 event & 55 & (3.4) & 52 & $(2.9)$ & $1.48(0.92-2.41)$ \\
\hline Q1: 1 to 3,210 events & 428 & (26.6) & 428 & $(24.2)$ & $1.17(0.93-1.47)$ \\
\hline Q2: 3,211 to 6,642 events & 381 & (23.6) & 434 & $(24.6)$ & $0.97(0.78-1.21)$ \\
\hline Q3: 6,643 to 13,679 events & 396 & (24.6) & 414 & $(23.4)$ & $1.07(0.86-1.32)$ \\
\hline \multirow[t]{2}{*}{ Q4: 13,680 to $94,886.67$ events } & 351 & $(21.8)$ & 438 & $(24.8)$ & 1.00 (reference) \\
\hline & & & & & $p$-trend $=0.41$ \\
\hline \multicolumn{6}{|l|}{ CDuration $^{\mathrm{C}}$} \\
\hline None: 0 hour & 55 & (3.4) & 52 & $(2.9)$ & $1.55(0.96-2.52)$ \\
\hline Q1: 1 to 4,497 hours & 397 & (24.6) & 429 & $(24.3)$ & $1.12(0.89-1.42)$ \\
\hline Q2: 4,498 to 9,711 hours & 407 & (25.3) & 428 & $(24.2)$ & 1.09 (0.87-1.36) \\
\hline
\end{tabular}


Table 4 Sensitivity analyses for the association between leisure-time sunlight exposure and prostate cancer, PROtEuS, Montreal, Canada (Continued)

\begin{tabular}{|c|c|c|c|c|c|}
\hline Q3: 9,712 to 18,459 hours & 426 & $(26.4)$ & 428 & $(24.2)$ & $1.24(0.99-1.54)$ \\
\hline \multirow[t]{2}{*}{ Q4: 18,460 to 103,484 hours } & 326 & $(20.2)$ & 429 & $(24.3)$ & 1.00 (reference) \\
\hline & & & & & $p$-trend $=0.30$ \\
\hline Considering winter leisure activities considered as non-exposed & 1904 & $(100)$ & 1962 & $(100)$ & \\
\hline \multicolumn{6}{|l|}{ CEvents $^{\mathrm{b}}$} \\
\hline None: 0 event & 60 & $(3.2)$ & 54 & $(2.8)$ & $1.47(0.93-2.35)$ \\
\hline Q1: 1 to 2,173 events & 499 & $(26.2)$ & 477 & $(24.3)$ & $1.19(0.96-1.48)$ \\
\hline Q2: 2,174 to 4,560 events & 430 & (22.6) & 477 & $(24.3)$ & $0.97(0.79-1.20)$ \\
\hline Q3: 4,561 to 9,103 events & 525 & (27.6) & 477 & $(24.3)$ & $1.24(1.01-1.52)$ \\
\hline \multirow[t]{2}{*}{ Q4: 9,104 to $52,991.5$ events } & 390 & $(20.5)$ & 477 & $(24.3)$ & 1.00 (reference) \\
\hline & & & & & $p$-trend $=0.34$ \\
\hline \multicolumn{6}{|l|}{ CDuration $^{c}$} \\
\hline None: 0 hour & 60 & $(3.2)$ & 54 & $(2.8)$ & $1.38(0.87-2.20)$ \\
\hline Q1: 1 to 2,987 hours & 455 & (23.9) & 477 & $(24.3)$ & $1.03(0.83-1.28)$ \\
\hline Q2: 2,988 to 6,790 hours & 474 & (24.9) & 477 & $(24.3)$ & $1.01(0.82-1.24)$ \\
\hline Q3: 6,791 to 12,479 hours & 492 & $(25.8)$ & 476 & $(24.3)$ & $1.14(0.93-1.40)$ \\
\hline \multirow[t]{2}{*}{ Q4: 12,480 to 94,933 hours } & 423 & $(22.2)$ & 478 & $(24.4)$ & 1.00 (reference) \\
\hline & & & & & $p$-trend $=0.46$ \\
\hline Using self-reported recreational sunlight exposure & 1904 & $(100)$ & 1962 & $(100)$ & \\
\hline None & 105 & $(5.5)$ & 117 & $(6.0)$ & $0.98(0.71-1.37)$ \\
\hline Sometimes & 708 & $(37.2)$ & 804 & $(41.0)$ & $0.91(0.79-1.06)$ \\
\hline Often & 1091 & $(57.3)$ & 1041 & $(53.1)$ & 1.00 (reference) \\
\hline
\end{tabular}

${ }^{\mathrm{a}}$ Odds ratio (OR), 95\% confidence interval (CI). Models adjusted for age, first-degree family history of prostate cancer, ancestry, timing of last prostate cancer screening, education, BMl, solar protection during leisure and overall physical activity level. Analyses excluding controls not screened for prostate cancer in the previous 2 years are not adjusted for prostate cancer screening. ${ }^{b} \mathrm{C} u m u l a t i v e$ number of events entailing sunlight exposure from age 18 years. ${ }^{\mathrm{C}} \mathrm{Cumulative}$ duration of leisure-time exposure to sunlight from age 18 years.

believed to have been largely non-differential, which tends to result in conservative estimates [39]. Questions on leisure activities were primarily formulated to assess energy expenditure and subjective judgment needed to be applied in a number of occasions when assigning them as indoor or outdoor activities. Physical activity is potentially related with $\mathrm{PCa}[40,41]$, and we adjusted for it in our analyses.

Reporting bias based on case-control status was possible, but unlikely. Sunlight exposure was not the primary focus of the PROtEuS study. Moreover, there is no widespread belief in the population that sunlight exposure is associated with PCa.

The vitamin D mechanism is most often called upon to explain a possible protective effect of sunlight exposure on PCa. Different pathways may be involved, such as decreased cell proliferation, cell cycle regulation, cell invasiveness and angiogenesis and increased cellular differentiation and apoptosis [42,43]. Although the evidence for an anti-cancer mechanism of vitamin D is strongly suggested by biological studies, it has not been consistently supported by epidemiological findings [44]. It is thus possible that other mechanisms exist between sunlight exposure and $\mathrm{PCa}$. One such mechanism, less documented in sunlight exposure studies, could be UV-induced nitric oxide [45]. At high concentrations, inhibitions of prostate cancer cell proliferation, of metastases and of epithelial-mesenchymal transition have been observed, and at low concentrations angiogenesis is promoted.

Should a relation between sunlight and PCa truly exist, and should this association involve vitamin D synthesis, then a number of factors would need to be considered for valid exposure assessment, such as skin coverage by clothing, skin type, geographical location and meteorological conditions [37]. First, the amount of skin exposed to the sun can determine the rate of vitamin synthesis and darker skins tend to allow for less vitamin D production [46]. However, previous data indicate that after a certain threshold, a greater exposed surface and a higher dose of UVB will not significantly increase vitamin D levels [47]. This could be explained by the negative feedback loop triggered by high levels of vitamin D, which involves its inactivation by the CYP24A1 hydroxylase 
[42]. Second, the amount of solar radiation received has been shown to differ between geographical regions, even when doing the same activity for the same amount of time [48]. Third, meteorological conditions such as the presence of direct, diffuse and reflected radiations, the time of the day and the atmospheric conditions [49] also affect the amount of solar radiation received. In addition, diet and supplementation play a role in the level of serum vitamin $D$, especially in the winter months when, at northern latitudes, no important vitamin $\mathrm{D}$ synthesis is triggered [50]. Information for these factors was not available for our study, so each recreational sunlight event was assumed here to be equal in terms of sunlight exposure dose.

Our study presents several important strengths. This is the largest study to date to assess the association between sunlight exposure, using an assessment protocol that takes into account individual sunlight-related behavior, and PCa. Moreover, the exposure assessment covered the entire adulthood period, something rarely achieved in the past. Cases were histologically confirmed, and information was collected as part of face-to-face interviews. Participation rates in the study were relatively good, compared to those often observed in similar studies. We were able to compare socio-demographic characteristics of eligible men who declined to participate in the study, to those of study subjects; only slight differences were observed, suggesting that strong selection bias was not at play. We collected information on a wide range of potential confounders and considered these in our analyses. This included the use of solar protection, which few studies have been able to take into account $[18,20]$.

\section{Conclusion}

Overall, there was little evidence in our data of an association between leisure-time exposure to sunlight during adulthood, and PCa development. Men never exposed to sunlight tended to show somewhat higher risks than those highly exposed, but confidence intervals included the null value and there was no dose-response pattern. These observations applied to both non-aggressive and aggressive PCa. Further studies of PCa based on refined sunlight exposure assessment protocols taking into account individual variations should be undertaken. Should sunlight exposure be shown to be linked to PCa risk, either negatively or positively, such a finding would be of high public health importance.

\section{Additional files}

Additional file 1: Ethics statement.

Additional file 2: Table S1. List of entries of leisure activities not predefined in the general questionnaire, PROtEuS, Montreal, Canada.

\section{Abbreviations}

AIC: Akaike information criterion; BMI: Body mass index; CDuration: Cumulative duration of sunlight exposure during leisure activities during adulthood; CEvents: Cumulative number of leisure activity events entailing sunlight exposure during adulthood; $\mathrm{Cl}$ : Confidence intervals; OR: Odds ratios: PCa: Prostate cancer; PROtEuS: Prostate cancer \& environment study; SD: Standard deviation.

\section{Competing interests}

The authors declare that they have no competing interests.

\section{Authors' contributions}

JY was involved in the design of the study, carried the statistical analyses and wrote the manuscript. $J L$ contributed to the design of the study and revised the manuscript. MEP conceived the overall PROtEuS study, and revised the manuscript. All authors have directly participated in the planning, execution, and analysis of the study. All authors read and approved the final manuscript.

\section{Acknowledgements}

The authors wish to sincerely thank the entire Epidemiology and Biostatistics team at INRS-Institut Armand-Frappier for their contribution to the study. Special thanks go to Drs. Deborah Weiss and Mariam El-Zein for useful comments on the manuscript. This study was supported financially through grants from the Canadian Cancer Society, the Cancer Research Society, the Fonds de la recherche du Québec - Santé (FRQS), FRQS-RRSE, and the Ministère du Développement économique, de l'Innovation et de I'Exportation du Québec. Marie-Élise Parent and Jérôme Lavoué hold career awards from the FRQS

\section{Author details}

${ }^{1}$ Department of Environmental and Occupational Health, Université de Montréal, Montreal, Quebec, Canada. ${ }^{2}$ INRS-Institut Armand-Frappier, Université du Québec, Laval, Québec H7V 1B7, Canada.

Received: 20 February 2014 Accepted: 17 July 2014

Published: 28 July 2014

\section{References}

1. Prostate cancer statistics. [http://www.cancer.ca/en/cancer-information/cancertype/prostate/statistics/?region=qc]

2. Hsing AW, Chokkalingam AP: Prostate cancer epidemiology. Front Biosci 2006, 11:1388-1413.

3. Brawley OW: Prostate cancer epidemiology in the United States. World J Urol 2012, 30(2):195-200

4. Haenszel W, Kurihara M: Studies of Japanese migrants. I. Mortality from cancer and other diseases among Japanese in the United States. J Natl Cancer Inst 1968, 40(1):43-68.

5. Maskarinec G, Noh Jj: The effect of migration on cancer incidence among Japanese in Hawaii. Ethn Dis 2004, 14(3):431-439.

6. Grant WB: An ecological study of cancer incidence and mortality rates in France with respect to latitude, an index for vitamin $D$ production. Dermatoendocrinol 2010, 2(2):62-67.

7. Anderson LN, Cotterchio M, Kirsh VA, Knight JA: Ultraviolet sunlight exposure during adolescence and adulthood and breast cancer risk: a population-based case-control study among Ontario women. Am J Epidemiol 2011, 174(3):293-304.

8. John EM, Schwartz GG, Koo J, Wang W, Ingles SA: Sun exposure, vitamin D receptor gene polymorphisms, and breast cancer risk in a multiethnic population. Am J Epidemiol 2007, 166(12):1409-1419.

9. Boscoe FP, Schymura MJ: Solar ultraviolet-B exposure and cancer incidence and mortality in the United States, 1993-2002. BMC Cancer 2006, 6:264

10. Colli JL, Grant WB: Solar ultraviolet B radiation compared with prostate cancer incidence and mortality rates in United States. Urology 2008, 71(3):531-535

11. Loke TW, Seyfi D, Khadra M: Prostate cancer incidence in Australia correlates inversely with solar radiation. BJU Int 2011, 108(Suppl 2):66-70.

12. Taksler GB, Cutler DM, Giovannucci E, Smith MR, Keating NL: Ultraviolet index and racial differences in prostate cancer incidence and mortality. Cancer 2013, 119(17):3195-3203. 
13. Waltz $P$, Chodick G: Assessment of ecological regression in the study of colon, breast, ovary, non-Hodgkin's lymphoma, or prostate cancer and residential UV. Eur J Cancer Prev 2008, 17(3):279-286.

14. John EM, Schwartz GG, Koo J, Van Den Berg D, Ingles SA: Sun exposure, vitamin $D$ receptor gene polymorphisms, and risk of advanced prostate cancer. Cancer Res 2005, 65(12):5470-5479.

15. John EM, Dreon DM, Koo J, Schwartz GG: Residential sunlight exposure is associated with a decreased risk of prostate cancer. J Steroid Biochem Mol Biol 2004, 89-90(1-5):549-552.

16. John EM, Koo J, Schwartz GG: Sun exposure and prostate cancer risk: evidence for a protective effect of early-life exposure. Cancer Epidemiol Biomarkers Prev 2007, 16(6):1283-1286.

17. Lin SW, Wheeler DC, Park Y, Cahoon EK, Hollenbeck AR, Michal Freedman D, Abne CC: Prospective study of ultraviolet radiation exposure and risk of cancer in the U.S. Int J Cancer 2012, 178(4):521-533.

18. Gilbert R, Metcalfe C, Oliver SE, Whiteman DC, Bain C, Ness A, Donovan J, Hamdy F, Neal DE, Lane JA, Martin RM: Life course sun exposure and risk of prostate cancer: population-based nested case-control study and meta-analysis. Int J Cancer 2009, 125(6):1414-1423.

19. Chia SE, Wong KY, Cheng C, Lau W, Tan PH: Sun exposure and the risk of prostate cancer in the Singapore prostate cancer study: a case-control study. Asian Pac J Cancer Prev 2012, 13(7):3179-3185.

20. Nair-Shalliker V, Smith DP, Egger S, Hughes AM, Kaldor JM, Clements M, Kricker A, Armstrong BK: Sun exposure may increase risk of prostate cancer in the high UV environment of New South Wales, Australia: A case-control study. Int J Cancer 2012, 131(5):E726-E732.

21. Peters CE, Nicol A-M, Demers PA: Prevalence of exposure to solar ultraviolet radiation (UVR) on the job in Canada. Can J Public Health 2012 103(3):223-226

22. Parent M-É, Goldberg MS, Crouse DL, Ross NA, Chen H, Valois M-F, Liautaud A: Traffic-related air pollution and prostate cancer risk: a case-control study in Montreal, Canada. Occup Environ Med 2013, 70(7):511-518.

23. Statistics Canada: "French and the francophonie in Canada." "2011 Analytical products." Census. Last updated 9 January 2013. [http://www12.statcan.gc. ca/census-recensement/2011/as-sa/98-314-x/2011003/tbl/tbl3_1-2-eng.cfm] Ottawa; accessed 23 July 2014.

24. Gleason Score. [http://gleasonscore.net/]

25. Burnham KP, Anderson DR: AIC Differences, $\Delta \mathbf{i}$. In Model Selection and Multimodel Inference. 2nd edition. Edited by Burnham KP. New York: Springer Science + Business Media, Inc; 2002:70-71.

26. Wright JL, Salinas CA, Lin DW, Kolb S, Koopmeiners J, Feng Z, Stanford JL: Prostate cancer specific mortality and gleason 7 disease differences in prostate cancer outcomes between cases with gleason $4+3$ and gleason $3+4$ tumors in a population based cohort. J Urol 2009, 182(6):2702-2707.

27. R: A Language and Environment for Statistical Computing. [http://www. R-project.org/]

28. Meyer D, Zeileis A, Hornik K: vcd: Visualizing Categorical Data R, R Foundation for Statistical Computing. R package version 1.2-13 edition. 2012.

29. Hanchette $\mathrm{CL}$, Schwartz GG: Geographic patterns of prostate-cancer mortality - evidence for a protective effect of ultraviolet radiation. Cancer 1992, 70(12):2861-2869.

30. Mizoue T: Ecological study of solar radiation and cancer mortality in Japan. Health Phys 2004, 87(5):532-538.

31. Grant WB, Garland CF: The association of solar ultraviolet B (UVB) with reducing risk of cancer: multifactorial ecologic analysis of geographic variation in age-adjusted cancer mortality rates. Anticancer Res 2006, 26(4A):2687-2699.

32. Freedman DM, Dosemeci M, McGlynn K: Sunlight and mortality from breast, ovarian, colon, prostate, and non-melanoma skin cancer: composite death certificate based case-control study. Occup Environ Med 2002, 59(4):257-262

33. Robsahm TE, Tretli S, Dahlback A, Moan J: Vitamin D-3 from sunlight may improve the prognosis of breast-, colon- and prostate cancer (Norway). Cancer Causes Control 2004, 15(2):149-158.

34. Nair-Shalliker V, Smith D, Egger S, Clements M, Rahman MB, Armstrong B: The association of ultraviolet radiation-B (305 nm), season of diagnosis, and latitude on the survival outcome of prostate cancer in the high UV environment of Australia. Cancer Causes Control 2013, 24(11):2005-2011.

35. Bodiwala D, Luscombe CJ, French ME, Liu S, Saxby MF, Jones PW, Ramachandran S, Fryer AA, Strange RC: Susceptibility to prostate cancer: studies on interactions between UVR exposure and skin type. Carcinogenesis 2003, 24(4):711-717.

36. Rothman KJ, Greenland S, Lash TL: Modern Epidemiology. 3rd edition. Philadelphia, PA: Lippincott Williams \& Wilkins; 2008.

37. Engelsen $\mathrm{O}$ : The relationship between ultraviolet radiation exposure and vitamin D status. Nutrients 2010, 2(5):482-495.

38. Fradet $Y$, Klotz L, Trachtenberg J, Zlotta A: The burden of prostate cancer in Canada. Can Urol Assoc J 2009, 3(3-S2):S92-S100.

39. Jurek AM, Greenland S, Maldonado G, Church TR: Proper interpretation of non-differential misclassification effects: expectations vs observations. Int J Epidemiol 2005, 34(3):680-687.

40. Friedenreich $\mathrm{C}$, Neilson $\mathrm{H}$, Lynch B: State of the epidemiological evidence on physical activity and cancer prevention. Eur J Cancer 2010, 46(14):2593-2604.

41. Parent M-É, Rousseau M-C, El-Zein M, Latreille B, Désy M, Siemiatycki J: Occupational and recreational physical activity during adult life and the risk of cancer among men. Cancer Epidemiol 2011, 35(2):151-159.

42. Donkena KV, Young CY: Vitamin d, sunlight and prostate cancer risk. Adv Prev Med 2011, 2011:281863.

43. Fleet JC, Desmet $M$, Johnson $R$, Li Y: Vitamin D and cancer: a review of molecular mechanisms. Biochem J 2012, 441(1):61-76.

44. Gilbert R, Martin R, Beynon R, Harris R, Savovic J, Zuccolo L, Bekkering G, Fraser W, Sterne JC, Metcalfe C: Associations of circulating and dietary vitamin $\mathrm{D}$ with prostate cancer risk: a systematic review and dose-response meta-analysis. Cancer Causes Control 2011, 22(3):319-340.

45. Burke AJ, Sullivan FJ, Giles FJ, Glynn SA: The yin and yang of nitric oxide in cancer progression. Carcinogenesis 2013, 34(3):503-512.

46. Godar DE, Pope SJ, Grant WB, Holick MF: Solar UV doses of adult americans and vitamin D3 production. Dermato-Endocrinol 2011, 3(4):243-250.

47. Bogh MKB, Schmedes AV, Philipsen PA, Thieden E, Wulf HC: Interdependence between body surface area and ultraviolet $B$ dose in vitamin D production: a randomized controlled trial. Br J Dermato/ 2011 164(1):163-169.

48. Downs N, Parisi A, Schouten P: Basal and squamous cell carcinoma risks for golfers: an assessment of the influence of tee time for latitudes in the Northern and Southern hemispheres. J Photochem Photobiol B 2011, 105(1):98-105

49. Webb AR: Who, what, where and when-influences on cutaneous vitamin D synthesis. Prog Biophys Mol Biol 2006, 92(1):17-25.

50. Webb AR, Kline L, Holick MF: Influence of season and latitude on the cutaneous synthesis of vitamin D3: exposure to winter sunlight in boston and edmonton will not promote vitamin D3 synthesis in human skin. J Clin Endocrinol Metab 1988, 67(2):373-378.

doi:10.1186/1471-2458-14-756

Cite this article as: Yu et al:: Sunlight exposure during leisure activities and risk of prostate cancer in Montréal, Canada, 2005-2009. BMC Public Health 2014 14:756.

\section{Submit your next manuscript to BioMed Central and take full advantage of:}

- Convenient online submission

- Thorough peer review

- No space constraints or color figure charges

- Immediate publication on acceptance

- Inclusion in PubMed, CAS, Scopus and Google Scholar

- Research which is freely available for redistribution 